\title{
Assessing the Health Status of Students at Université Des Montagnes in Cameroon
}

\author{
Bruno Ela Ondo ${ }^{1,2, *}$, Jonas Kouamouo ${ }^{1}$, Ashu Michael Agbor ${ }^{1}$, Ernest Tambo ${ }^{1}$ and Lazare Kaptué ${ }^{1}$ \\ ${ }^{1}$ Université des Montagnes (UdM), Bangangté, Cameroon \\ ${ }^{2}$ Marseille Medical School, St Joseph Hospital, Marseille, France
}

*Corresponding author: Bruno Ela Ondo, 21, Rue Friedland Bat B2 Les Estudines \# 415, Marseille 13006, France, Tel: 0033754375993; E-mail: eondo@live.com; bela@udm.aed-cm.org

Received: 09 Jun, 2020 | Accepted: 23 Jun, 2020 | Published: 03 Jul, 2020

Citation: Ela OB, Kouamouo J, Agbor AM, Tambo E, Kaptué L (2020) Assessing the Health Status of Students at Université Des Montagnes in Cameroon. J Epidemiol Public Health Rev 5(3): dx.doi.org/10.16966/2471-8211.195

Copyright: (c) 2020 Ela OB, et al. This is an open-access article distributed under the terms of the Creative Commons Attribution License, which permits unrestricted use, distribution, and reproduction in any medium, provided the original author and source are credited.

\begin{abstract}
Introduction: We usually believe that young adults in general, are a population that is healthier. As a result, in low middle income countries, public health policy-makers pay little attention to student's health status. However, this assumption may undermine the academic performance of some college students.

Objective: The aim of our study is to describe the health status of the UdM students, during the 2016-2017 academic year.

Methods: We used a multi-stratified random sample of about five hundred students. We assessed both clinical and biological data available in the students' health records.

Results: When considering signs and symptoms of disease based on clinical and biological findings, about $25.0 \%$ of students were in good health. The proportions of clinical signs and symptoms varied between 0.4 to $21.9 \%$, with high blood pressure prevailing the most. Students who drank alcohol beverages from occasional to frequent use, were estimated at $34.8 \%$. The prevalence of hepatitis B and C virus was $12.8 \%$ and $1.4 \%$ respectively; while $12.4 \%$ of blood sugar was above the cutting point of $1.20 \mathrm{~g} / \mathrm{l}$ and $8.0 \%$ of students were overweight. Anemia from all etiologies was estimated at $15.5 \%$; allergy, cardio-pulmonary, and digestive disorders were found at $14.8 \%, 13.1 \%$ and $10.6 \%$ respectively.

Conclusion: Findings from this pioneered research in a low middle income country raised awareness that college students in UdM, like their counterparts elsewhere, are experiencing health disparities; calling public health decision-makers to increase their actions for better care and value
\end{abstract} in student's health.

Keywords: Health status; College-aged population; Descriptive; Clinical and biological characteristics; Stratified random sample

\section{Introduction}

In high income countries, the rationale behind some colleges and universities for having a healthcare clinic relies on the need to help the students perform at their best and achieve academic success, making students' well-being a major public health commitment [1]. While in low middle income countries, a common opinion boldly suggests that college-aged population is healthier.

However findings from research studies conducted abroad in some college sittings have revealed health disparity as a common issue among college students. It was in this context that the University of New Hampshire in the United States of America (US) has developed the CHANAS project for College Health and Nutrition Assessment Survey. The project aims at collecting and analyzing data from students. The confidential data from each student participant includes Anthropometric values; Biochemical indices; Clinical data; Dietary information, and more [2]. In addition, Ehlinger Ed [3] of the University of Minnesota, in his presentation, underscored the relevance for mandating health insurance to college and university students for the purpose of reducing health disparities. He also provided information on how these "mandatory insurance" policies could help reduce disparities in health status of American students [3]. Buhi ER, et al. [4] had conducted a research on "Sexual and Reproductive Health Disparities in a National Sample of Hispanic and Non-Hispanic White United States College Students" using data from ACHA-NCHA II (American College Health Association National College Health Assessment) data. The ACHA-NCHA $[4,5]$ is conducted every year across the US public and private colleges and Universities. The survey assesses a variety of health outcomes and behaviors relevant to college-aged populations.

More recently on April 2019, Elflein J [6] has published statistics and facts on the health status of the USA college students. The assessment was done on important issues such as diseases and disabilities, drug 
and alcohol use, mental health issues such as depression, suicide and self-inflicted harm; and risk factors like condom use and vaccinations [6].

In Africa, there is a paucity of published researches on health status of college aged-populations. Nevertheless, Omage K, et al. [7] had carried out in 2018 an assessment of dietary pattern and nutritional status of undergraduate students in a private university in southern Nigeria. They also assessed students' alcohol and tobacco use.

In Cameroon, we were unable to find a published research work on the ground of college students' health status assessment. Thus, to reverse this pattern, we carry out a cross-sectional descriptive investigation that sheds light on the prevalence of common disease symptoms and signs that may affect college students at the Université des Montagnes. We describe students' heath status as "good or fair" in accordance with the proportions of clinical and biological indices; leading to the main objective of this study to illustrate that students at the UdM like their counterparts worldwide, can experience health disparity.

\section{Methods}

\section{Setting and study participants}

Participants consisted of college-aged students between fifteen and thirty-year-old, from the UdM who attended the university's clinics for a mandated health screening, which took place from October 2015 to January 2016. It is estimated that about two thousand students underwent this academic medical visit. The UdM is a private university, located in the Western region of Cameroon and made up of several schools like medicine, pharmacy, veterinary, dentistry, biology, paramedics, biomedical engineering, mathematics and finances, telecommunication, clean energy, and architectures. Students from these training programs were enrolled in our final sample.

\section{Ethical considerations}

We were granted not only an approval from the institutional review board but, also informed consents from student's delegates. Because one of the delegates declined to provide consent therefore, we removed not only his file, but also those of his classmates from the final sample. In order to prevent the leak of student health record from occurring, we preserved the student's health privacy first, by removing student's identifiers from the file, then assigning a numeric code to each file, next establishing a list of students' names that matched with the numeric codes of each file and finally we kept the list in a secret place.

\section{Study design}

The design of our study is an observational descriptive crosssectional study of both clinical and biological data available solely in the students' health records, filed at the University's clinics established during the mandated health screening.

Inclusion criteria: Were retained all files that belonged to the UdM students who have participated to the mandatory medical visit of the 2016-2017 academic year.

Exclusion criteria: We rejected any student file that was altered or empty.

Sampling method and sampling size: We randomly sampled about five hundred clinical files. First, we stratified a poll of eight hundred files according to the region of student's origin. The first stratum was made up of two main regions, western and non-western regions; then, we stratified each region by gender to make the second stratum of four groups; next, we proceeded with a random selection of each third file at a regular interval known as the period. Using the period of 3, we removed every third file of a series of three from each four groups of the last stratum, making about three hundred files. Thus, the final sample was made up of the remaining five hundred files, a stratified randomized sample that provided the best picture of the UdM students. Since the number of students from western region was three times higher than those from the non-western, we managed to preserve the ratio of $3 / 1$ in favor of the western region in our final sample. It is relevant to state that the ratio male/female student was $1 / 1$ in each region.

\section{Indicators}

We were three accredited physicians who collected data of disease symptoms, student past medical history and lifestyles, and family medical history by interviewing each student. The disease signs were collected during the physical examination. All data including the results of blood and urine analyses were recorded and stored in the student health file.

Sociodemographic values: They are described as the following variables:

- Region of student's origin: West region and others (North, Farnorth, South, Center, East, North-west, Adamaoua, South-west and Littoral region).

- Age at the time the study was conducted, is described as a quantitative variable and qualitative categorized as inferior to 23-year-old for junior and superior or equal to 23-year-old for senior students.

- Gender, a qualitative variable that is categorized as female and male.

Clinical data: Disease was referred to as "fair health" which means the presence of one or many signs and/or symptoms, in the other words anything that looks abnormal to the well-being status such as chronic fatigue, lack of appetite, pain, during the physical exam like cardiac arrhythmia, heart murmur, whizzing, high blood pressure, increased size of an organ; presence of protein, sugar and blood in urine, abnormal levels of hemoglobin, sugar, white blood cell count, antigens and antibodies found in the blood work were in favor of disease suspicion. While "Excellent or good health" was referred to as nothing abnormal was reported. Symptoms and signs are either quantitative (blood pressure, hemoglobin, etc.) or qualitative variables.

- Body Mass Index (BMI) is normal if lower than $25 \mathrm{~kg} / \mathrm{m}^{2}$, otherwise overweight for both male and female. We brought the cutting point to $25 \mathrm{~kg} / \mathrm{m}^{2}$ in respect to the young age adult population.

- Blood pressure is normal when the systolic falls between 100 and $135 \mathrm{mmHg}$, and diastolic between 60 and $90 \mathrm{mmHg}$; high blood pressure is considered above the upper extreme for both systolic and diastolic pressures. Measurement was performed with an automated electronic devices and adjustable cuffs.

- Heart rate is normal between 60 and 100 beats per minute; above 100 beats is considered as tachycardia and below 60 beats as bradycardia.

- Student's lifestyles are qualitative variables such as alcohol beverage use, smoking, sexually active and parental status or pregnancies.

- Family medical history is a qualitative variable of diseases that run in the student's relatives.

Biological indices: The blood work and urinalysis were performed 
in the medical laboratory setting of the university clinic using appropriate testing methods and equipment such as the Siemens Clinitek status for urinalysis. The lab technicians who performed the analyses had at least five to ten years of experience on the job. Abnormal findings in levels of cell count, hemoglobin, blood glucose, serology and other signs of infection, etc., were recorded and findings of any abnormality in qualitative variable was quoted as "Yes" or "NO" for normal.

\section{Statistical analysis}

We use IBM-SPSS software version 20 to compute descriptive statistics of quantitative variables to yield the estimates of the Mean and Median for central tendency; the standard deviation describes the dispersion and variability of the data. We classified qualitative variables in "Yes or NO", for example, frequent or occasional use of alcohol is classified as "Yes", and never ever use as "No" to compute proportions. The approach of this study is solely descriptive; therefore, there is not a need to run statistical tests that would compute p-value as a decision making tools to deal with the uncertainty when making inferences with respect to studying correlations (t-test, Anova) or association (Chi-square test).

\section{Results and Discussion}

(Tables 1 to 5 )

Table 1: Descriptive statistics of quantitative variables in a total of 505 students.

\begin{tabular}{|l|c|c|c|c|c|c|c|}
\hline Variables & $\mathbf{N}$ & Median & Mean & STDEV & Min & Max & MD (\%) \\
\hline Age & 499 & 22.0 & 22.15 & 2.79 & 16 & 39 & $6(1.2)$ \\
\hline BMI & 48 & 23.40 & 24.08 & 3.42 & 17.36 & 30.76 & $457(90.5)$ \\
\hline Systolic & 452 & 123 & 124.41 & 13.38 & 96 & 172 & $53(10.5)$ \\
\hline Diastolic & 452 & 76.50 & 76.75 & 9.88 & 50 & 110 & $53(10.5)$ \\
\hline HR & 452 & 75 & 76.85 & 14.97 & 48 & 160 & $53(10.5)$ \\
\hline Glycemia & 339 & 104 & 105.04 & 15.28 & 60 & 196 & $166(32.9)$ \\
\hline HB & 341 & 13.50 & 13.64 & 1.90 & 6.1 & 21.3 & $164(32.5)$ \\
\hline RBC & 257 & 5.37 & 5.32 & .74 & 2.18 & 8.67 & $248(49.1)$ \\
\hline HCT & 243 & 47.00 & 46.40 & 6.33 & 19.3 & 72.6 & $262(51.9)$ \\
\hline MCV & 347 & 87.6 & 87.18 & 5.95 & 51.1 & 105.3 & $158(31.3)$ \\
\hline WBC & 329 & 5.8 & 6.01 & 1.63 & 2.0 & 13.6 & $176(34.9)$ \\
\hline Platelets & 344 & 283.0 & 290.67 & 78.76 & 28 & 689 & $161(31.9)$ \\
\hline
\end{tabular}

$\mathrm{N}=$ Number; $\quad \mathrm{MD}=$ Missing $\quad$ Data; $\%=$ Percentage; STDEV=Standard Deviation; Min=Minimum; Max=Maximum; $B M l=B o d y$ Mass Index (overweight if higher than $\left.25 \mathrm{~kg} / \mathrm{m}^{2}\right)$; HR=Heart Rate $(60-100$ beats per minute); HB=Hemoglobin (12-17g/dl); RBC=Red Blood Cells (4000-6000/ $\left.\mathrm{mm}^{3}\right) ; \mathrm{HCT}=$ Hematocrit (38-50\%); MCV=Mean Corpuscular Volume (80-95 fl); WBC=White Blood Cell $\left(4000-10000 / \mathrm{mm}^{3}\right)$; Platelets $\left(150-450 / \mathrm{mm}^{3}\right)$; Blood S.=Blood Sugar (0.7-1.10 g/l); Systolic blood pressure=100-135 $\mathrm{mmHg}$; Diastolic $=60-90 \mathrm{mmHg}$.

Note: The values provided in the legend are the normal ranges.

- Each variable follows a distribution that is approximately normal.

- The average estimate of each variable falls within the normal range. High volume of missing data (MD) with $90.5 \%$ for the BMI since the height and weight from few students were obtained.
Table 2: Description of sociodemographic indicators in a total of 505 students.

\begin{tabular}{|c|c|c|c|c|c|}
\hline Variables & Categories & $\mathbf{N}$ & Proportion \% & Total (\%) & MD (\%) \\
\hline \multirow[t]{2}{*}{ Gender } & M & 250 & 50.2 & \multirow{2}{*}{ 498(98.6) } & \multirow{2}{*}{$7(1.4)$} \\
\hline & $\mathrm{F}$ & 248 & 49.8 & & \\
\hline \multirow{2}{*}{$\begin{array}{l}\text { Age } \\
\text { (year) }\end{array}$} & $<23$ & 282 & 56.5 & \multirow{2}{*}{ 499(98.8) } & \multirow{2}{*}{$6(1.2)$} \\
\hline & $\geq 23$ & 217 & 43.5 & & \\
\hline \multirow{2}{*}{$\begin{array}{l}\text { Region of } \\
\text { origin }\end{array}$} & others & 138 & 27.7 & \multirow{2}{*}{ 498(98.6) } & \multirow{2}{*}{$7(1.4)$} \\
\hline & West & 360 & 72.3 & & \\
\hline
\end{tabular}

$\mathrm{N}=$ Number; $\mathrm{MD}=$ Missing Data; \%=Percentage; $\mathrm{M}=$ Male; $\mathrm{F}=$ Female; $<=$ Lower than; $\geq$ =Higher or equal; others=non-west regions; Junior college students are younger than 23 year-old, senior college students are 23 year-old and above.

- Sex ratio is $1 / 1$; both sexes are well represented.

- Age ratio for younger and elder is $1.30 / 1$, slightly in favor of younger students.

- Regional ratio is $2.61 / 1$ in favor of the West.

\section{Disease Prevalence in UdM student community}

This study showed that about one quarter, $25.0 \%$ of students did not display a clinical and/or biological sign or symptom of the disease; therefore, we might assume that their health status was "good or excellent". The prevalence of the excellent health status is two-fold higher compare to $13.0 \%$ of US students [6], with the same average in age of $22.15 \pm 2.8$ and $22.73 \pm 6.0$ year-old for UdM and US students respectively. However, the standard deviation shows more precision in the UdM estimate.

\section{Clinical characteristics}

Disease profile through clinical signs and symptoms showed High blood pressure as the most frequently displayed sign, followed by cardio-pulmonary, allergy, ophthalmology and digestive complaints; while, a lack of appetite, fatigue and psychiatric symptoms were scant. This finding is inconsistent with the US College students' health survey of 2018 [5], where allergy, sinus infections, back pain and psychiatric diseases were common at $21.0 \% ; 16.4 \% ; 11.9 \% ; 9.3 \%$ respectively; only $3.1 \%$ of students had Hypertension. However, the prevalence of High blood pressure in our study appears consistent with what is known as $24.8 \%$ in people aged above 18-year-old in Cameroon [8].

While body mass index (BMI) is viewed as risk factor for High blood pressure and carbohydrate intolerance, our findings showed that $35.4 \%$ of students appear to be overweight at the cutting point of $25 \mathrm{~kg} / \mathrm{m}^{2}$ and only $8.3 \%$ of them might be obese at the cutting point of $30 \mathrm{~kg} / \mathrm{m}^{2}$. When considering the young age of UdM students, this finding is pretty well in line with the WHO 2016 data [9] that found the prevalence of overweight at $29.7 \%$ nationally in people aged above eighteen. Data from the WHO and Index Mundi of 2016 showed that $9.5 \%$ and $11.4 \%$ respectively of adult Cameroonians are obese $[10,11]$. In the US where obesity is a major public health issue, $57.9 \%$ of students were found to have a healthy weight $[5,6]$, suggesting that the BMI may not be a prominent risk factor of Hypertension in the US student community.

Sickle Cell Disease, commonly affects people of African descends and its prevalence among UdM student is consistent with the $2.9 \%$ worldwide reported by the WHO [12]. On the other hand, the proportion of Allergic reactions among UdM students was in the lower limit of the data provided by the World Allergy Organization, 
Table 3: Clinical parameters in a total of 505 students with 248 females for Ob/Gyn

\begin{tabular}{|c|c|c|c|c|c|}
\hline Variables & Categories & $\mathbf{N}$ & $\begin{array}{c}\text { Proportion } \\
\%\end{array}$ & Total (\%) & MD (\%) \\
\hline \multirow{2}{*}{$\begin{array}{l}\text { Disease signs } \\
\text { and symptoms }\end{array}$} & No & 107 & 24.7 & \multirow{2}{*}{$434(85.9)$} & \multirow{2}{*}{ 71(14.1) } \\
\hline & yes & 327 & 75.3 & & \\
\hline \multirow{2}{*}{ BMI $\left(\mathrm{kg} / \mathrm{m}^{3}\right)$} & $<25$ & 31 & 64.6 & \multirow{2}{*}{$48(8.5)$} & \multirow{2}{*}{$457(91.5)$} \\
\hline & $\geq 25$ & 17 & 35.4 & & \\
\hline \multirow{2}{*}{ HBP } & No & 353 & 78.1 & \multirow{2}{*}{$452(89.5)$} & \multirow{2}{*}{$53(10.5)$} \\
\hline & Yes & 99 & 21.9 & & \\
\hline \multirow{2}{*}{ Appetite } & No & 2 & 0.4 & \multirow{2}{*}{$448(88.7)$} & \multirow{2}{*}{$57(11.3)$} \\
\hline & Yes & 446 & 99.6 & & \\
\hline \multirow{2}{*}{ Asthenia } & No & 437 & 97.5 & \multirow{2}{*}{$448(88.7)$} & \multirow{2}{*}{$57(11.3)$} \\
\hline & Yes & 11 & 2.5 & & \\
\hline \multirow{2}{*}{ Neurology } & No & 439 & 98 & \multirow{2}{*}{$448(88.7)$} & \multirow{2}{*}{$57(11.3)$} \\
\hline & Yes & 9 & 2 & & \\
\hline \multirow{2}{*}{ Ophthalmology } & No & 392 & 87.7 & \multirow{2}{*}{$447(88.5)$} & \multirow{2}{*}{$58(11.5)$} \\
\hline & Yes & 55 & 12.3 & & \\
\hline \multirow{2}{*}{ Rheumatology } & No & 429 & 96.2 & \multirow{2}{*}{$446(88.3)$} & \multirow{2}{*}{$59(11.7)$} \\
\hline & Yes & 17 & 3.8 & & \\
\hline \multirow{2}{*}{ Ear Nose Throat } & No & 416 & 93.3 & \multirow{2}{*}{$446(88.3)$} & \multirow{2}{*}{ 59(11.7) } \\
\hline & Yes & 30 & 6.7 & & \\
\hline \multirow{2}{*}{ Endocrinology } & No & 439 & 98.9 & \multirow{2}{*}{ 444(87.9) } & \multirow{2}{*}{$61(12.1)$} \\
\hline & Yes & 5 & 1.1 & & \\
\hline Cardio- & No & 386 & 86.9 & 1918701 & $61 / 1211$ \\
\hline Pulmonary & Yes & 58 & 13.1 & $81.9)$ & 61 \\
\hline & No & 398 & 89.4 & & \\
\hline Digestive & Yes & 47 & 10.6 & $444(8 / .9)$ & $60(12.1)$ \\
\hline Oh/Gunocoloru & No & 214 & 96.4 & 01 & 26 \\
\hline Ud/ synecology & Yes & 8 & 3.6 & 59.51 & U.5) \\
\hline Nenhro urology & No & 433 & 97.1 & $196(802)$ & $50(117)$ \\
\hline Ivepnro-urology & Yes & 13 & 2.9 & (88.3) & 1.7) \\
\hline & No & 428 & 96.2 & & \\
\hline D & Yes & 17 & 3.8 & $3.1)$ & \\
\hline & No & 441 & 99.3 & & \\
\hline Psyc & Yes & 3 & 0.7 & $444(8 / .9)$ & $61(12.1$ \\
\hline
\end{tabular}

$\mathrm{N}=$ Number; $\mathrm{MD}=$ Missing Data; \% Percentage; Ob/Gyn=Obstetrics and Gynecology (248 female students); HBP=High Blood Pressure (Systolic $>135 \mathrm{mmHg}$; Diastolic $>90 \mathrm{mmHg}$ ); variable categories were defined by the presence (Yes=fair health) or absence ( $\mathrm{No}=$ excellent health) of disease signs and symptoms.

- $\quad 75.3 \%$ of UdM students have at least one sign and/or symptom of disease. The proportion of disease signs and/or symptoms vary between 0.4 to $21.9 \%$, with high blood pressure (HBP) being the most frequently displayed followed by cardio-pulmonary, ophthalmology and digestive symptoms with $21.9 \%, 13.1 \%, 12.3 \%$, and $10.6 \%$ respectively; conversely lack of appetite, fatigue and psychiatric symptoms were scant at $0.4 \%, 2.5 \%, 0.7 \%$ respectively.

- $\quad$ BMI ratio is $2 / 1$ in favor of normal body weight; however, $91.50 \%$ of $\mathrm{MD}$, compared to $1.2 \%$ for age.

- Missing data ranged from $10.5 \%$ to $14.1 \%$ for gynecology and disease signs and symptoms variable respectively; when the $\mathrm{BMI}$ is not taken into account.
Table 4: Student's lifestyle, past and family medical history indicators in a total of 505 students with 248 females for Pregnancy.

\begin{tabular}{|c|c|c|c|c|c|}
\hline Variables & Categories & $\mathbf{N}$ & Proportion (\%) & Total (\%) & MD (\%) \\
\hline \multirow{2}{*}{ Tobacco use } & No & 436 & 98 & \multirow{2}{*}{$445(88.1)$} & \multirow{2}{*}{$60(11.9)$} \\
\hline & Yes & 9 & 2 & & \\
\hline \multirow{2}{*}{ Alcohol use } & No & 291 & 65.2 & \multirow{2}{*}{$446(88.3)$} & \multirow{2}{*}{$59(11.7)$} \\
\hline & Yes & 155 & 34.8 & & \\
\hline \multirow{2}{*}{$\begin{array}{l}\text { Sexually } \\
\text { active }\end{array}$} & No & 148 & 45.5 & \multirow{2}{*}{$325(64.5)$} & \multirow{2}{*}{$180(35.5)$} \\
\hline & Yes & 177 & 54.5 & & \\
\hline \multirow{2}{*}{ Pregnancy } & No & 194 & 89.4 & \multirow{2}{*}{$217(87.5)$} & \multirow{2}{*}{$31(12.5)$} \\
\hline & Yes & 23 & 10.6 & & \\
\hline \multirow{2}{*}{ Allergy } & No & 379 & 85.2 & \multirow{2}{*}{$445(88.1)$} & \multirow{2}{*}{$60(11.9)$} \\
\hline & Yes & 66 & 14.8 & & \\
\hline \multirow{2}{*}{$\begin{array}{l}\text { Sickle Cell } \\
\text { Disease }\end{array}$} & No & 430 & 97.5 & \multirow{2}{*}{$441(87.3)$} & \multirow{2}{*}{$64(12.7)$} \\
\hline & Yes & 11 & 2.5 & & \\
\hline \multirow{2}{*}{$\begin{array}{l}\text { Cancer in } \\
\text { Family }\end{array}$} & No & 427 & 96.2 & \multirow{2}{*}{$444(87.9)$} & \multirow{2}{*}{$61(12.1)$} \\
\hline & Yes & 17 & 3.8 & & \\
\hline \multirow{2}{*}{$\begin{array}{l}\text { Diabetes in } \\
\text { Family }\end{array}$} & No & 350 & 78.7 & \multirow{2}{*}{$445(88.1)$} & \multirow{2}{*}{$60(11.9)$} \\
\hline & Yes & 95 & 21.3 & & \\
\hline \multirow{2}{*}{$\begin{array}{l}\text { CVD in } \\
\text { Family }\end{array}$} & No & 326 & 73.6 & \multirow{2}{*}{$443(87.7)$} & \multirow{2}{*}{$62(12.3)$} \\
\hline & Yes & 117 & 26.4 & & \\
\hline
\end{tabular}

$\mathrm{N}=$ number $\quad$ or Frequency; $\mathrm{MD}=$ Missing Data; \%=Percentage; $\mathrm{CVD}=$ Cardiovascular Diseases; Yes=student has that past medical history, $\mathrm{No}=$ Student do not have or use it, no matter the frequency or quantity of the issue.

- When considering students' lifestyle, we found out that $34.8 \%$ of students is alcoholic; when only $2.0 \%$ has tobacco smoking habits.

- Although $53.0 \%$ had had sexual intercourse experience, however only $10.0 \%$ of female students had a past history of pregnancy.

MD varies from $11.7 \%, 12.5 \%$ to $35.5 \%$ on alcohol, pregnancy and sexual activity respectively.

it is estimated between $10-40 \%$ worldwide and $20 \%$ in the United Kingdom [13].

When considering students' lifestyle, we found out that one third of UdM students drinks alcoholic beverage, varying from occasional (less than five beers per month) to frequent use (more than five beers per week); conversely, very few students have tobacco smoking habits. Those results are in line with the findings of Omage $\mathrm{K}$ et al. [7] in a study conducted at a private university of southern Nigeria, where $30.5 \%$ and $5.0 \%$ of students did take alcohol and smoked tobacco respectively [7]. In the US, the proportion of students involved in alcohol use was $78.8 \%$ and tobacco use as cigarette, E-cigarette, and water pipe was $20.0 \%, 18.6 \%$, and $17.4 \%$ respectively [5]. In addition, analysis of students' sexual conduct showed that half of them had experienced a sexual encounter and ten percent of female students had a past history of pregnancy. The proportion of sexual activity appears slightly lower compared to their US counterparts where vaginal intercourse was estimated at $64.2 \%$ in the 2018 survey [5]. UdM students' family history well corroborates with other clinical findings with cardio-pulmonary and high blood pressure being the leading trends. 
Table 5(a): Biological parameters in a total of 505 students.

\begin{tabular}{|c|c|c|c|c|c|}
\hline Variables & Categories & $\mathbf{N}$ & $\begin{array}{c}\text { Proportion } \\
\%\end{array}$ & Total (\%) & MD (\%) \\
\hline \multirow{2}{*}{ Hepatitis B Virus } & No & 300 & 87.2 & \multirow{2}{*}{$344(68.1)$} & \multirow{2}{*}{ 161(31.9) } \\
\hline & Yes & 44 & 12.8 & & \\
\hline \multirow{2}{*}{ Hepatitis C Virus } & No & 341 & 98.6 & \multirow{2}{*}{$346(68.5)$} & \multirow{2}{*}{$159(31.5)$} \\
\hline & Yes & 5 & 1.4 & & \\
\hline \multirow{2}{*}{ Blood sugar } & Normal & 297 & 87.6 & \multirow{2}{*}{$339(67.1)$} & \multirow{2}{*}{$166(32.9)$} \\
\hline & High & 42 & 12.4 & & \\
\hline \multirow{2}{*}{ Hemoglobin } & Normal & 288 & 84.5 & \multirow{2}{*}{$341(67.5)$} & \multirow{2}{*}{$164(32.5)$} \\
\hline & Low & 53 & 15.5 & & \\
\hline \multirow{2}{*}{ MCV } & Normal & 315 & 90.8 & \multirow{2}{*}{$347(68.7)$} & \multirow{2}{*}{$158(31.3$} \\
\hline & Abnormal & 32 & 9.2 & & \\
\hline \multirow{2}{*}{ Hematocrit } & Normal & 214 & 88.1 & \multirow{2}{*}{$243(48.1)$} & \multirow{2}{*}{$262(51.9)$} \\
\hline & Abnormal & 29 & 11.9 & & \\
\hline \multirow{2}{*}{ Red Blood Cells } & Normal & 279 & 69.6 & \multirow{2}{*}{$257(50.9)$} & \multirow{2}{*}{$248(49.1$} \\
\hline & Abnormal & 78 & 30.4 & & \\
\hline \multirow{2}{*}{$\begin{array}{l}\text { White Blood } \\
\text { Cells }\end{array}$} & Normal & 312 & 94.8 & \multirow{2}{*}{$329(65.1)$} & \multirow{2}{*}{$176(34.9$} \\
\hline & Abnormal & 17 & 5.2 & & \\
\hline \multirow{2}{*}{ Platelets } & Normal & 332 & 96.5 & \multirow{2}{*}{$344(68.1)$} & \multirow{2}{*}{$164(31.9$} \\
\hline & Abnormal & 12 & 3.5 & & \\
\hline \multirow{2}{*}{$\begin{array}{l}\text { Inverted } \\
\text { formula }\end{array}$} & No & 127 & 36.9 & \multirow{2}{*}{$344(68.1)$} & \multirow{2}{*}{ 161(31.9) } \\
\hline & Yes & 217 & 63.1 & & \\
\hline \multirow{4}{*}{ Group } & $A$ & 82 & 23.8 & \multirow{4}{*}{$345(68.3)$} & \multirow{4}{*}{$160(31.7)$} \\
\hline & B & 70 & 20.3 & & \\
\hline & $A B$ & 10 & 2.9 & & \\
\hline & $\mathrm{O}$ & 183 & 53 & & \\
\hline & Negative & 8 & 2.3 & () & \\
\hline knes & Positive & 338 & 97.7 & . & 13 \\
\hline
\end{tabular}

$\mathrm{N}=$ Number; $\mathrm{MD}=$ Missing Data; \%=Percentage; $\mathrm{MCV}=$ Mean Corpuscular Volume was low if $<80 \mathrm{fl}$ otherwise normal; Yes=student has the biological sign, No=Student do not have it. Blood sugar was high if $>1.20 \mathrm{~g} / \mathrm{l}$ otherwise normal; Hemoglobin was low if $<12 \mathrm{~g} / \mathrm{dl}$ otherwise normal; Hematocrit was low if $<38 \%$ otherwise normal; Red blood cell count was low if $<4000 / \mathrm{ml}$ otherwise normal; White blood cell count was low if $<4000 / \mu$ l otherwise normal; Platelet count was low if $<150.000 / \mu \mathrm{l}$; Inverted formula when Lymphocyte count was higher than Neutrophil count. Hepatitis B and C virus are "yes" when antibodies and or antigens are positive in the blood, "No" otherwise.

- The prevalence of Hepatitis B Virus (HBV) among UdM students was $12.8 \%$ (44 students of 344 screened), when $\mathrm{HBs}$ antigen ( $\mathrm{HBs} \mathrm{Ag}$ ) and $\mathrm{HBC}$ antibody ( $\mathrm{HBC} \mathrm{Ab})$ were used simultaneously. However, when HBs $\mathrm{Ag}$ was used alone the number of students tested positive was 9 among 344 screened students representing a prevalence of $2.6 \%$. Furthermore, all nine students with a positive $\mathrm{HBs} \mathrm{Ag}$ also have $\mathrm{HBc} \mathrm{Ab}$; therefore, $10.2 \%$ (35 students among 344 ) has a positive $\mathrm{HBc}$ Ab alone.

- The proportion of blood sugar above the cutting point of $1.20 \mathrm{~g} / \mathrm{l}$ was $12.4 \%$; it fell at $8.0 \%, 5.0 \%$ and $1.5 \%$ when all screened blood sugar was above the cutting point of $1.25 \mathrm{~g} / \mathrm{l}, 1.30 \mathrm{~g} / \mathrm{l}$ and $1.40 \mathrm{~g} / \mathrm{l}$ respectively (results not shown).

- The prevalence of anemia from all etiology was estimated at $15.5 \%$, considering $\mathrm{Hb}$ level below $12.0 \mathrm{~g} / \mathrm{dl}$ for both sexes.

- The proportion of blood group O, A, B and AB was as follow 53.0\%, $23.8 \%, 20.3 \%$ and $2.9 \%$ respectively.

- With respect to rhesus distribution, $97.7 \%$ of students have a positive phenotype, while $2.3 \%$ is negative.

- Inverted white blood cell (WBC) count accounted for $63.1 \%$ of all blood work.

- MD varies between $31.3 \%$ and $51.9 \%$ for Mean corpuscular volume and Hematocrit respectively.
Table 5(b): Results of the analysis of urine in a total of 505 students.

\begin{tabular}{|c|c|c|c|c|c|}
\hline Variables & Categories & $\mathbf{N}$ & $\begin{array}{c}\text { Proportion } \\
\%\end{array}$ & Total (\%) & MD (\%) \\
\hline \multirow{2}{*}{ Urinalysis } & Normal & 250 & 67.4 & \multirow{2}{*}{$371(73.5)$} & \multirow{2}{*}{$134(26.5)$} \\
\hline & Abnormal & 121 & 32.6 & & \\
\hline \multirow{2}{*}{ Proteins } & No & 313 & 85.3 & \multirow{2}{*}{$367(72.8)$} & \multirow{2}{*}{$138(27.2)$} \\
\hline & Yes & 54 & 14.7 & & \\
\hline \multirow{2}{*}{$\begin{array}{l}\text { Red blood } \\
\text { cells }\end{array}$} & No & 301 & 87.5 & \multirow{2}{*}{$344(68.1)$} & \multirow{2}{*}{ 161(31.9) } \\
\hline & Yes & 43 & 12.5 & & \\
\hline \multirow{2}{*}{ Nitrites } & No & 336 & 90.8 & \multirow{2}{*}{$370(73.3)$} & \multirow{2}{*}{$135(26.7)$} \\
\hline & Yes & 34 & 9.2 & & \\
\hline \multirow{2}{*}{$\begin{array}{l}\text { White blood } \\
\text { cells }\end{array}$} & No & 303 & 88.1 & \multirow{2}{*}{$344(68.1)$} & \multirow{2}{*}{ 161(31.9) } \\
\hline & Yes & 41 & 11.9 & & \\
\hline \multirow{2}{*}{ Sugar } & No & 342 & 99.4 & \multirow{2}{*}{$344(68.1)$} & \multirow{2}{*}{ 161(31.9) } \\
\hline & Yes & 2 & 0.6 & & \\
\hline \multirow{2}{*}{ Ketones } & No & 148 & 95.5 & \multirow{2}{*}{$155(30.7)$} & \multirow{2}{*}{$350(69.3)$} \\
\hline & Yes & 7 & 4.5 & & \\
\hline
\end{tabular}

$\mathrm{N}=$ Number; $\mathrm{MD}=$ Missing data; \%=Percentage

- Urinalysis showed that $32.6 \%$ of student was abnormal. The leading causes were proteinuria, hematuria and white blood cells at $14.7 \%$; $12.5 \% ; 11.9 \%$ respectively; whereas glycosuria was found to be $0.6 \%$.

- MD was estimated at $26.5 \%$ of all urinalysis with ketone bodies being the most at $69.3 \%$.

\section{Biological characteristics}

Our findings showed that the prevalence of Hepatitis B virus could be underestimated, when the HBs antigen is used alone as a screening method. In order to get the true estimate, both $\mathrm{HBs}$ antigen and $\mathrm{HBc}$ antibody should be tested simultaneously. In addition, we found that all students who were tested positive for $\mathrm{HBs}$ antigen also had serum $\mathrm{HBc}$ antibody, suggesting that infected students were transitioning from acute to chronic phase of the disease. At the national level, Hepatitis $B$ virus is screened using HBs antigen alone and the prevalence varies between 10.1 and $11.2 \%[14,15]$, which appears four-fold higher compared to UdM student community. We suggest that HBs antigen and $\mathrm{HBc}$ antibody be considered simultaneously to accurately estimate the prevalence of Hepatitis $\mathrm{B}$ virus infection in Cameroon. On the other hands, the prevalence of Hepatitis $\mathrm{C}$ virus among UdM students was lower compared to $4.8 \%$ nationally [15], but higher compared to US college students $0.3 \%$ for both hepatitis B and C [5].

Carbohydrate intolerance testing shows the prevalence at $12.4 \%$ and $5.0 \%$ when the cutting point of blood sugar was above $1.20 \mathrm{~g} / \mathrm{l}$ and $1.30 \mathrm{~g} / \mathrm{l}$ respectively. Nationally, the prevalence of diabetes is $5.8 \%$ [16], making the cutting point of $1.30 \mathrm{~g} / \mathrm{l}$ more in line with the prevalence of diabetes in Cameroon, a country where the majority of the population is less than 25-year-old [9]. Again, we cannot accurately assume that $12.4 \%$ of UdM students are intolerant to carbohydrates, but our study showed that $8.0 \%$ of screened blood sugar was higher, above the cutting point of $1.25 \mathrm{~g} / \mathrm{l}$. That prevalence is higher than $1.1 \%$ of US college students [5]. Although the fasting status of some UdM students might be questionable, it is relevant to state the majority of students had spent two or three hours in the clinic waiting for a physical examination. Thus, when considering this long period in the waiting room, the 
blood sugar may have dropped or returned to normalcy, making the fasting status an irrelevant issue for many students. In addition, there was not a vending machine available around for candies, sweet drinks or foods.

Iron deficiency anemia (IDA) is a major public health issue in developing countries. IDA is mainly due to malnourishment of children and lack of supplement in pregnant women. The prevalence of anemia from all etiologies is estimated at $15.5 \%$ among the UdM students. This finding is two to four-time lower than what has been reported in Cameroon for other age groups; it is between 60.0 to $68.0 \%$ in children under 5 -year-old and $39.5 \%$ in women aged between 15 and 49-year-old [9]. In Yemen, the overall prevalence of IDA was $30.4 \%$ among college students [17]. In Cameroon, IDA remains the main etiology of anemia. In rural Cameroon, Sop MM, et al. [18] had detected anemia in $66.7 \%$ of the children and IDA was found in $51.4 \%$ [18]. Thus, compared to their Yemenite counterparts and other age groups in Cameroon, UdM students are doing better; an evidence that they may be pretty well-nourished since the majority if not all are from middle to high income family.

Urinalysis showed that one third of student had abnormal urine with the leading abnormalities in ascending order being proteinuria, hematuria, white blood cells and glycosuria. Those results are inconsistent with Topham PS, et al. [19] work in the United Kingdom who found $6.2 \%$ of urine abnormality in a young adult population with a mean age of 21-year-old; although the observed abnormality was only on protein and hematuria or both with $3.8 \%, 1.7 \%$ and $0.6 \%$ respectively; glycosuria was not found [19]. Our findings in UdM students are five-time higher, although some of our results might be questionable; however, we matched female students' last menstrual period with the occurrence of hematuria to rule out any false positive. In addition, the presence of both WBC and nitrites being too close at $11.9 \%$ and $9.2 \%$ respectively was in favor of urinary tract infection (UTI); a proportion in line with 9.5\% UTI reported in US students' health assessment [5].

\section{Genetic profile of blood elements}

In our study, UdM students follow the blood group profile that was described by the findings of American Red Cross in 2019, which found $51.0 \%$ of African-Americans to have blood group O phenotype versus $47.0 \%$ for Caucasians and $57.0 \%$ for Spanish population [20]. In Cameroon, Ndoula ST, et al. [21] too, reported the proportion of blood groups $\mathrm{O}, \mathrm{A}, \mathrm{B}$ and $\mathrm{AB}$ at $48.5 \%, 25.1 \%, 21.9 \%$ and $4.5 \%$, respectively [21]. On the other hand, rhesus distribution showed the prevalence of positive rhesus phenotype in the UdM community being also in line with the results from Ndoula ST, et al. [21] who found $96.3 \%$ of positive rhesus phenotype in Cameroon population. However, those proportions are higher than $94.0 \%$ reported worldwide [22].

Finally, the proportion of inverted WBC among UdM students was consistent with what is commonly known as "Benign Ethnic Neutropenia" [23,24], seen in people of African descents compared to their counterparts of European descents. According to Reich D, et al. [24] the explanation of this finding relies on the genetic variant of the Duffy Null polymorphism rs2814778 at chromosome 1q23.2; a polymorphism known to protect against Plasmodium vivax malaria. The African, or "null," form of this variant represses the expression of the "Duffy Antigen Receptor for Chemokines" on red blood cells, leading to impaired regulation of neutrophil growth or migration [24].

\section{Study Limitations}

Study designed after the data were collected by Physicians who were not instructed to perform similarly leading to missing data like body mass index. In addition, some blood sugar tests were not performed according to the rule of the art, making difficult to accurately distinguish fasting and non-fasting status. Furthermore, quality control of blood pressure screening and laboratory equipment may be questionable, making differential misclassification bias likely.

\section{Study Advantage}

We conducted a well-designed and pioneering study among college-aged community in Cameroon to provide Epi data. A representative large sample size has help thwart the impact of missing data and increased accuracy and precision of statistical estimates, like exemplified by a more leptokurtic distribution of our observations around the mean-age compared to the US.

\section{Conclusion}

While UdM students' health status at some clinical and biological standpoints might be slightly different from what had been described elsewhere, especially in high resource countries like the US; our findings clearly suggest that UdM students, too, are experiencing health disparities that are proper to their environment. Seven students over ten have a fair health and only three over ten have an excellent health status. The leading symptoms and signs of disease are high blood pressure, allergic reactions, cardio-pulmonary, digestive, ophthalmology, anemia, and carbohydrate intolerance. In addition, misconducts in lifestyle and disease prevention were observed with high proportion of students being involved in the use of alcoholic beverage and sexual activities.

Although the ultimate purpose of this research study was solely to describe our findings, but never ever to make any comparative analysis with study like ACHA-NCHA II; however, our hope is to make the findings of this pioneered research a tool that would raise awareness to public health policy makers, reminding them that college-aged students in Cameroon like abroad, can experience health conditions that remain unsung for public health policy. Therefore, it may be the time to set up a National Students' Health Surveys at Elementary, Secondary and College levels in Cameroon. For that purpose, this is what the American College Health Assessment-National College Health Assessment stands for. "The ACHA-National College Health Assessment II is a national research survey organized by the American College Health Association (ACHA) to assist college health service providers, health educators, counselors, and administrators in collecting data about their students' habits, behaviors, and perceptions on the most prevalent health topics. The ACHA-NCHA now provides the largest known comprehensive data set on the health of college students, providing the college health and higher education fields with a vast spectrum of information on student health."

Thus, we are calling public health decision-makers to more actions for better care and value in student's health in Cameroon by bridging across the Ministry of Higher, Secondary, Basic education and Public health, to set up a program that plays a similar role in Cameroon [25].

\section{Author Contribution \\ - $\quad$ Bruno Ela Ondo (Ela OB) $70 \%$ \\ - Jonas Kouamouo (Kouamouo J) $15 \%$ \\ - Ashu Michael Agbor (Agbor MA) 11\% \\ - $\quad$ Ernest Tambo (Tambo E) $2 \%$ \\ - $\quad$ Lazare Kaptué (Kaptue L) 2\%}




\section{Acknowledgments}

We would like to express our sincere gratitude to the students who granted their consents to this research, and the reviewers who took the time to make this work near perfect; we do appreciate your expertise and good will.

\section{Author Disclaimers}

The authors do not have any conflict of interest to disclose and there was any funding granted to this research.

\section{References}

1. Swinford PL (2002) Advancing the Health of Students: A Rationale for College Health Programs. J Am Coll Health 50: 309-312.

2. College Health and Nutrition Assessment Survey (CHANAS) (2016) University of New Hampshire, Durham, United States.

3. Ehlinger Ed (2002) Reducing health disparities: A case for mandatory insurance for college students. The $130^{\text {th }}$ Annual Meeting of APHA. Serving Teens and Young Adults in Their Local and College Communities.

4. Buhi ER, Marhefka SL, Hoban MT (2010) The State of the Union: Sexual Health Disparities in a National Sample of US College Students. J Am Coll Health 58: 337-346.

5. American College Health Association (2018) Spring 2018: Reference Group Executive Summary. ACHA, United States.

6. Elflein J (2019) College student health-Statistics \& Facts. Statista, Hamburg, Germany.

7. Omage K, Omuemu Vo (2018) Assessment of Dietary Pattern and Nutritional Status of Undergraduate Students in a Private University in Southern Nigeria. Food Sci Nutr 6: 1890-1897.

8. Nelson TF, Gortmaker SL, Subramanian SV, Cheung L, Wechsler H (2007) Disparities in Overweight and Obesity among US College Students. Am J Health Behav 31: 363-373.

9. World Health Organization, African Health Observatory (2016) Health Analytical Profile 2016 Cameroon. Yaounde, Cameroon.

10. World Health Organization (2016) Global Health Observatory data repository. Geneva, Switzerland.

11. Index Mundi (2016) Cameroon obesity-adults prevalence rate. CIA World Factbook.

12. Chemegni BC, Kenmegne AB, Ngo SFN, Ngouadjeu E, Megningue NE, et al. (2018) Epidemiological, Clinical and Biological Characteristics of Cameroonian Children and Adolescents with Sickle-Cell Anemia. Arch Med 10: 1-3.

13. Canonica GW, Cox L, Pawankar R, Baena-Cagnani CE, Blaiss M, et al. (2013) Sublingual Immunotherapy: World Allergy Organization Position Paper 2013 Update. World Allergy Organ 7: 6.

14. Bigna JJ, Amougou MA, Asangbeh SL, Kenne AM, Noumegni SRN, et al. (2017) Seroprevalence of Hepatitis B Virus Infection in Cameroon: A Systematic Review and Meta-Analysis. BMJ Open 7: e015298.

15. Noubiap JJN, Joko WYA, Nansseu JRN, Tene UG, Siaka C (2013) Seroepidemiology of Human Immunodeficiency Virus, Hepatitis B and C Viruses, and Syphilis Infections among First-Time Blood Donors in Edéa, Cameroon. Int J Infect Dis 17: e832-e837.

16. Bigna JJ, Nansseu JR, Katte JC, Noubiap JJ (2018) Prevalence of Prediabetes and Diabetes Mellitus among Adults Residing in Cameroon: A Systematic Review and Meta-Analysis. Diabetes Res Clin Pract 137: 109-118.

17. Al-Alimi AA, Bashanfer S, Morish MA (2018) Prevalence of Iron Deficiency Anemia among University Students in Hodeida Province, Yemen. Anemia 2018: 4157876.

18. Sop MMK, Mananga MJ, Tetanye E, Gouado I (2015) Risk factors of anemia among young children in rural Cameroon. Int Curr Microbiol App Sci 4: 925-935.

19. Topham PS, Jethwa A, Watkins M, Rees Y, Feehally J (2004) The Value of Urine Screening in a Young Adult Population. Fam Pract 21: 18-21.

20. American Red Cross (2019) Facts about blood and blood types: Not all blood is alike. Unites States.

21. Ndoula ST, Noubiap JJN, Nansseu JRN, Wonkam A (2014) Phenotypic and Allelic Distribution of the $A B O$ and Rhesus (D) Blood Groups in the Cameroonian Population. Int J Immunogenet 41: 206-210.

22. Rhesus Negative (2012) Blood Type Frequencies by Country including the Rh Factor.

23. Grann VR, Ziv E, Joseph CK, Neugut Al, Wei Y, et al. (2008) Duffy (Fy), DARC, and Neutropenia among Women from the United States, Europe and the Caribbean. Br J Haematol 143: 288-293.

24. Reich D, Nalls MA, Kao WHL, Akylbekova EL, Tandon A, et al. (2009) Reduced Neutrophil Count in People of African Descent is due to a Regulatory Variant in the Duffy Antigen Receptor for Chemokines Gene. PLoS Genet 5: e1000360.

25. Ciotoli C, Smith AJ, Keeling RP (2018) Call to Action: Better Care, Better Health, and Greater Value in College Health. J Am Coll Health 66: 625-639. 